\title{
PENGARUH SARINGAN BUDI DAYA IKAN DI SALURAN (SARIBAN) TERHADAP KOMUNITAS BENTOS
}

\author{
Krismono*, Endi Setiadi Kartamihardja*), dan Sutandar Zaenal ${ }^{* *}$
}

\begin{abstract}
Abstrak
Penelitian ini bertujuan untuk mengetahui pengaruh budi daya ikan di saluran irigasi (sariban) terhadap komunitas bentos. Penelitian dilakukan di saluran irigasi Kawista, Telagasari, Karawang, dan analisis laboratorium dilakukan di Inlitkanwar Jatiluhur. Metode penelitian survai dengan sampling fisika, kimia, dan biologis dilakukan di tujuh stasiun penelitian yang terletak di aliran sebelum dan sesudah sariban. Hasil penelitian menunjukkan bahwa di saluran irigasi ditemukan 17 jenis makrozoobentos yaitu: Pleurocera acuta, Goniobasis livescen, Tryonia sp., Lioplax subcarinata, Gryrotoma amplum, Lithasia sp., Pomacea calignosa, Physa gyrima, Gyraulus sp. (Kelas Gastropoda $=57.61 \%)$, Simpsoniconcha sp., Spaerium simile $($ Kelas Pelesipoda $=8.71 \%)$, Pseudodiamesa sp., Berosus striatius, Dashyhelea sp., Culicoides variipenneis (kelas Insekta = $10.02 \%$ ), Lumbriculus sp., Branchiura sowerbyi (Kelas Oligokaeta $=23.66 \%$ ). Kelimpahan bentos terpengaruh oleh aktivitas sariban yaitu kelimpahannya menurun pada stasiun sariban dan meningkat kembali setelah sariban. Kualitas air, khususnya BOD juga terpengaruh yaitu naik pada sariban dan setelah sariban kembali menurun.
\end{abstract}

\begin{abstract}
Influence of sariban (fish culture in irrigation canal) on benthos community. By: Krismono. Endi Setiadi Kartamihardja, and Sutandar Zaenal.

The aim of the research was to know the influence of sariban on the benthos community. The research was conducted in secondary irrigation canal Kawista, Telagasari Karawang area, West Java, and in the laboratory of Research Station for Freshwater Fisheries Jatiluhur West Java from October to December 1998. Method of the research was survey by sampling method, to obtain data on physico-chemical and biological parameters at seven stations at direction of flow through, after and before sariban. The results showed that 17 species macrozoobenthos were found in the irrigation canal i.e Pleurocera acuta, Goniobasis livescen, Lioplax subcarinata, Gyrotoma amplum, Tryonia sp., Lithosia sp., Pomacea calignosa, Physa gyrina, Gyraulus sp. (including class Gastropoda 57.61\%), Simpsoniconcha sp., Spaerium simile (including class Pelecypoda $8.71 \%$ ), Pseudodiamesa sp., Berosus striatus, Dashyhelea sp., Culicoides variipennis (including class Insecta 10.02\%), and Lumbriculus sp., Branchiura sowerbyi (including class Oligochaeta $23.66 \%)$. The abundance of benthos was decreased in stations at sariban and was increased in those located after sariban, on the other hand $B O D$ values was increased in stations sariban and decreased in those after sariban.
\end{abstract}

KEYWORDS: sariban, community, benthos

\section{PENDAHULUAN}

Peningkatan produksi ikan masih terus diusahakan untuk meningkatkan kebutuhan konsumsi ikan yang telah mencapai $19 \mathrm{~kg} / \mathrm{kapita} / \mathrm{tahun}$ pada tahun 1995 , namun konsumsi rata-rata perkapita untuk propinsi terpadat yaitu Jawa masih di bawah rata-rata (Anonim, 1997), sehingga diperlukan teknologi dan lahan yang dapat digunakan untuk tujuan tersebut. Salah satu lahan yang sampai sekarang belum mendapat perhatian dan berpotensi sebagai lahan untuk memproduksi ikan adalah saluran irigasi. Indonesia sebagai salah satu negara agraris mempunyai sumber daya saluran irigasi cukup besar. Sebagai contoh perairan Waduk Jatiluhur mempunyai saluran induk sepanjang
$240 \mathrm{~km}$ dan saluran sekunder sekitar $1.200 \mathrm{~km}$ dengan luas total 1.114.350 ha (Anonim, 1998).

Menurut Barnes \& Mann (1991), perairan saluran irigasi merupakan perairan yang subur dan banyak mengandung pakan alami ikan, antara lain berupa organisme-organisme dasar perairan, khususnya makrozoobentos di samping zooplankton.

Suatu sistem budi daya ikan di saluran irigasi yang sedang dikembangkan di wilayah pengairan waduk Jatiluhur adalah sistem saringan budi daya ikan di saluran (sariban). Ikan dipelihara di saluran irigasi pada panjang saluran tertentu yang diberi batas (saringan) dengan konstruksi yang dapat dibuat dari bambu, besi atau kawat. Keunggulan budi daya ikan sistem

\footnotetext{
Peneliti pada Balai Penelitian Perikanan Air Tawar

**) Pengajar pada Universitas Pajajaran
} 
sariban adalah ikan yang dibudidayakan tidak diberi pakan. Hasil pemeliharaan ikan tawes. nila. dan mas di saluran irigasi Jatisari. Karawang, dengan menanam benih berukuran $30 \mathrm{~g} /$ ekor dengan total penebaran $600 \mathrm{~kg}$ setelah dipelihara selama tiga bulan dicapai bobot rata-rata 200 g/ekor (total $1800 \mathrm{~kg}$ ) pada panjang saluran sekitar 500 m dan lebar 20 m (Anonim, 1998).

Pemeliharaan ikan di sariban dengan tidak diberi pakan akan mempengaruhi komunitas bentos yang ada di saluran irigasi, sehingga dampak sariban terhadap komunitas bentos di saluran irigasi ada. Oleh karena itu perlu dilakukan penelitian pengaruh sariban terhadap komunitas bentos di saluran irigasi.

Penelitian ini bertujuan untuk mengetahui pengaruh sariban terhadap kualitas air saluran irigasi dan populasi bentos di saluran irigasi Telagasari, Karawang.

\section{BAHAN DAN METODE}

Penelitian dilaksanakan pada bulan Oktober sampai dengan Desember 1998, di saluran irigasi sekunder Kawista yang terletak di Kecamatan Telagasari, Kabupaten Karawang. Sedangkan analisis laboratorium dilaksanakan di Laboratorium Instalasi Penelitian Perikanan Air Tawar Jatiluhur

Jenis ikan yang dipelihara di sariban adalah ikan nila (Oreochromis niloticus), tawes (Barbus gonionotus), dan jambal siam (Pangasius hypophthalmus), dengan ukuran bobot benih masingmasing 45-50 g/ekor, dan biomassa tiap jenis $36 \mathrm{~kg}$. Ukuran sariban yang digunakan adalah panjang 36 m, lebar 6 m, dan kedalaman 0,7 m. Ikan dipelihara dalam sariban tanpa diberi pakan. Parameter yang diukur dapat dilihat pada Tabel 1. Alat yang digunakan untuk identifikasi bentos adalah loupe dan identifikasi menggunakan buku Pennak (1978) dan Throp \& Covich (1991). Contoh makrozoobentos diawetkan menggunakan formalin $4 \%$.

Pengambilan sample air dilakukan di stasiun । (daerah sebelum sariban). Stasiun II (dalam sariban), dan untuk melihat pengaruh di hilir sariban dilakukan pengamatan pada 5 stasiun secara eksponensial jarak dari sariban (Klemm, 1990) yaitu : Stasiun III(1 m) IV $(5 m), V(25 m), V I(125 m)$, dan VII (625m) Pengambilan sampel dilakukan setiap dua minggu sebanyak enam kali pengamatan selama Oktober sampai Desember 1998

\section{Analisis data}

\section{Analisis struktur komunitas makrozoobentos :}

\section{Kelimpahan jenis makrozoobentos dihitung berdasarkan rumus(Odum, 1971)}

$$
K=\frac{10.000 \times a}{b}
$$

dengan:

$\mathrm{K}=$ Kelimpahan makrozoobentos (ind $/ \mathrm{m}^{2}$ )

$\mathrm{a}=$ Jumlah makrozoobentos (ind.)

$\mathrm{b}=$ Luas bukaan Eiman grab $\left(\mathrm{cm}^{2}\right)$

Untuk membandingkan kelimpahan makrozoobentos antar stasiun digunakan uji nonparametrik

Tabel 1. Parameter yang diukur.

Table 1. Measured parameter.

\begin{tabular}{lcc}
\hline \multicolumn{1}{c}{$\begin{array}{c}\text { Parameter } \\
\text { Parameters }\end{array}$} & $\begin{array}{c}\text { Satuan } \\
\text { Unit }\end{array}$ & $\begin{array}{c}\text { Alat dan metode } \\
\text { Instrument and method }\end{array}$ \\
$\begin{array}{l}\text { Kedalaman air } \\
\text { Water distance/depth } \\
\mathrm{pH}\end{array}$ & $\mathrm{cm}$ & Krisbow KL 886-3 \\
Kecepatan arus & unit & $\begin{array}{c}\mathrm{pH} \text {-meter Corning model-39 } \\
\text { Pelampung dan stopwach }\end{array}$ \\
Current velocity & $\mathrm{m} / \mathrm{sec}$ & Float and stopwatch \\
Oksigen terlarut (DO) & $\mathrm{mg} / \mathrm{L}$ & APHA, 1989 \\
$\begin{array}{l}\text { Disolved oksigen BOD } 5 \\
\text { Contoh lumpur }\end{array}$ & $\mathrm{mg} / \mathrm{L}$ & APHA, 1989 \\
Instruments mud sample & $\mathrm{mg} / \mathrm{m}$ & Ekman Grab (Wildo) \\
Sedimen & $\mathrm{mg} / \mathrm{m}$ & Saringan 100 um \\
Sedimen & & Filter \\
Makrozoobentos & individu & Saringan \\
Macrozoobenthos & & Filter \\
Contoh air & $\mathrm{L}$ & Water sampler \\
Water sample & & \\
\hline
\end{tabular}


Kruskal-Wallis (Nasution \& Barizi, 1985). Uji ini didasarkan pada fungsi yang berdistribusi khi-kuadrat,

$$
K_{n}=\frac{1}{n(n+1)}\left\{\left(\sum_{j=1}^{k} R / n i\right)-3(n+1)\right\}
$$

dengan derajat bebas $(\mathrm{db})=\mathrm{k}-1$ serta bersyarat bahwa $k$ contoh lebih dari dua

Keterangan

$\mathrm{K}_{\mathrm{N}}=$ Nilai uji Kruskal-Wallis

$\mathrm{N}$ = Banyaknya bentos dalam sample

$K=$ Jumlah stasiun

$\mathrm{R}=$ Jumlah pangkat

\section{Keanekaragaman makrozoobentos}

$$
H^{\prime}=-\sum_{i}^{N} p_{i} \ln p_{i}
$$

Keanekaragaman makrozoobentos dianalisis menggunakan perhitungan indeks Shannon-Weaver (Magurran, 1988) sebagai berikut

Keterangan

$H^{\prime}=$ Indeks keanekaragaman Shannon

$\mathrm{Pi}=$ proporsi individu yang terdapat pada spesies ke-i, dengan ni/N.

$\mathrm{Ni}=$ jumlah spesies ke-i

$\mathrm{N}=$ jumlah total spesies

\section{Keseragaman makrozoobentos}

$$
E=H^{\prime} / H \text { mak }=H^{\prime} \ln S
$$

Keterangan

$$
\begin{aligned}
& \mathrm{E} \quad=\text { Indeks keseragaman } \\
& \mathrm{H} \max =\ln \mathrm{S} \\
& \mathrm{S} \quad=\text { Jumlah spesies } \\
& \mathrm{H}^{\prime} \quad=\text { Indeks keanekaragaman }
\end{aligned}
$$

Defisit spesies ( Hellawell, 1989)

$$
I=\frac{S_{u}-S_{d}}{S_{u}} \times 100
$$

Keterangan

$S_{u}=$ Jumlah spesies di hulu sariban

$S_{d}=$ Jumlah spesies di hilir sariban

I=Indeks defisit spesies

\section{Analisis isi perut ikan}

Analisis makanan ikan dilakukan dengan menggunakan rumus Effendi (1978) sebagai berikut:

$$
I P=\frac{V_{i} \times O_{i}}{\sum\left(V_{i} \times O_{i}\right)} \times 100 \%
$$

Keterangan

$V=$ persentase volume satu macam makanan

$\mathrm{O}_{i}=$ persentase frekuensi kejadian satu macam makanan

$\mathrm{S}\left(\mathrm{V} \times \mathrm{O}_{i}\right)=\underset{\text { makanan }}{\text { jumlah }} \mathrm{V}_{i} \times \mathrm{O}_{i}$ dari semua macam

$\mathrm{IP}=$ Indeks of preponderance

\section{HASIL DAN BAHASAN}

\section{Kelimpahan makrozoobentos}

Dari hasil penelitian didapatkan 17 jenis makrozoobentos yang termasuk dalam kelas Gastropoda, Insekta, Oligokaeta, dan Pelesipoda seperti pada Tabel 2. Jenis-jenis tersebut yang dominan adalah Pleurocera acuta (Kelas Gastropoda), Simpsoniconcha sp. (Kelas Pelesipoda), Pseudodiamesa sp. (Kelas Insekta), dan Lumbriculus (Kelas Oligokaeta).

Makrozoobentos yang dominan di perairan ini adalah kelas Gastropoda yaitu 57,6\%. Sesuai dengan klasifikasi dari Wilhm (1975), kelas Gastropoda merupakan organisme yang fakultatif yaitu organisme yang tahan hidup pada perairan yang banyak mengandung bahan organik. Meskipun demikian hewan ini tidak dapat tahan terhadap tekanan lingkungan lainnya misalnya arus air yang kuat atau keadaan substrat yang tidak sesuai bagi kehidupan organisme tersebut.

Berdasarkan uji Kruskal-Wallis pada selang kepercayaan $95 \%$ diketahui bahwa nilai kelimpahan rata-rata makrozoobentos antar stasiun menunjukkan perbedaan yang nyata (Tabel 3). Hal ini karena adanya perubahan kondisi fisik dan kimia pada tiap stasiun di saluran irigasi yang digunakan untuk budi daya ikan sistem Sariban. Kondisi fisik dan kimia yang memungkinkan terjadinya perubahan kelimpahan dari makrozoobentos tersebut diperkirakan karena perbedaan kandungan tipe substrat dan dari perbedaan distribusi bahan organik yang berasal dari sisa metabolisme ikan yang sedang dibudidayakan. Sehingga kelimpahan makrozoobentos antar stasiun terlihat mempunyai kecenderungan penurunan kelimpahan makrozoobentos mulai dari stasiun I ke stasiun II, dan kenaikan kelimpahan makrozoobentos mulai dari stasiun II sampai dengan stasiun VII.

Kelimpahan makrozoobentos yang tertinggi terdapat pada stasiun VI yaitu sebesar $1.257 \mathrm{ind} . / \mathrm{m}^{2}$. Hal ini diduga disebabkan oleh besarnya kandungan bahan organik yang terdapat pada stasiun VI yang tercermin pada tingginya nilai BOD yaitu $3.9 \mathrm{mg} / \mathrm{L}$ (Lampiran 1). Pada stasiun ini kelas Pelesipoda dan Insekta mempunyai kelimpaham yang relatif lebih tinggi dibandingkan stasiun-stasiun lainnya, sedangkan kelimpahan terkecil terdapat pada stasiun 
Tabel2. Jenis dan kelimpahan makrozoobentos yang didapatkan di saluran irigasi Kawista, Karawang pada bulan Oktober - Desember 1998

Table 2. Kind and abundance of macrozoobenthos in Kawista Karawang irrigation canal on October until December 1998

\begin{tabular}{|c|c|c|c|c|c|c|c|c|c|}
\hline \multirow{2}{*}{$\begin{array}{l}\text { Nama bentos } \\
\text { Benthos name }\end{array}$} & \multicolumn{7}{|c|}{ Stasiun (station) } & \multirow{2}{*}{$\begin{array}{l}\text { Jumlah } \\
\text { Total }\end{array}$} & \multirow{2}{*}{$\%$} \\
\hline & $\mathrm{I}$ & II & III & IV & $\mathrm{V}$ & VI & VII & & \\
\hline Gastropoda & 1001 & 347 & 382 & 500 & 403 & 625 & 652 & 3910 & 57.6 \\
\hline Pleuracera acuta & 659 & 264 & 299 & 465 & 312 & 438 & 375 & 2812 & - \\
\hline Goniobasis livescen & 69 & - & - & 21 & - & - & 62 & 152 & - \\
\hline Lioplax subcarinata & 35 & - & 14 & - & 21 & 42 & 42 & 154 & - \\
\hline Gyrotoma amplum & 35 & 35 & 28 & - & 28 & - & 42 & 168 & - \\
\hline Tryonia sp. & 42 & 7 & - & - & - & 83 & 69 & 201 & - \\
\hline Lhitasia sp. & 69 & - & 28 & - & - & 14 & - & 111 & - \\
\hline Pomacea calignosa & 97 & - & 14 & 14 & 42 & - & 42 & 209 & - \\
\hline Physa gyrina & - & 21 & - & - & - & - & 21 & 42 & - \\
\hline Gyraulus sp. & - & 21 & - & - & - & 49 & - & 70 & - \\
\hline Pelecypoda & 132 & - & - & 7 & 35 & 271 & 146 & 591 & 8.71 \\
\hline Simposoniconcha sp. & 132 & - & - & - & 35 & 236 & 146 & 549 & - \\
\hline Sphaerium simile & - & - & - & 7 & - & 35 & - & 42 & - \\
\hline Insecta & 28 & 14 & 62 & 167 & 139 & 194 & 76 & 680 & 10.02 \\
\hline Pseudodiamesa sp. & 14 & 14 & 35 & 111 & 97 & 69 & 76 & 416 & - \\
\hline Berosus striatus & - & - & - & - & 42 & - & - & 42 & - \\
\hline Dasyhelea sp. & - & - & 25 & 21 & - & 125 & - & 171 & - \\
\hline Culicoides variipennis & 14 & - & - & 35 & - & - & - & 49 & - \\
\hline Oligochaeta & - & 56 & 174 & 382 & 507 & 167 & 320 & 1564 & - \\
\hline Lumbriculus sp. & - & 56 & 174 & 361 & 486 & 167 & 320 & 1564 & - \\
\hline Branchiura sowerbyi & - & - & - & 21 & 21 & - & - & 42 & - \\
\hline $\begin{array}{l}\text { Jumlah individu } \\
\text { Individu total }\end{array}$ & 1161 & 417 & 618 & 1057 & 1083 & 1257 & 1194 & 6787 & 100 \\
\hline $\begin{array}{l}\text { Jumlah spesies } \\
\text { Species total }\end{array}$ & 10 & 7 & 8 & 9 & 9 & 10 & 10 & - & - \\
\hline
\end{tabular}

II yaitu sebesar 417 ind. $/ \mathrm{m}^{2}$. Pada stasiun ini kelas Pelesipoda tidak ditemukan dan kelas Insekta menempati urutan kelimpahan terkecil yaitu sebesar
14 ind. $/ \mathrm{m}^{2}$. Hal ini diduga erat kaitannya dengan proses predasi oleh ikan yang dibudidayakan pada stasiun tersebut.

Tabel 3. Jumlah pangkat $(\mathrm{Rj})$, jumlah spesies $(\mathrm{Nj})$ dan jumlah total spesies $(\mathrm{N})$ di tiap stasiun menurut uji Kruskal-Wallis

Table 3. Sum of degree (Rj), sum of species $(N j)$ and total sum of species $(N)$ at each station based on Kruskal-Wallis test

\begin{tabular}{|c|c|c|c|c|c|c|c|}
\hline & \multicolumn{7}{|c|}{ Stasiun (Station) } \\
\hline & la & IIb & IIIc & Ivd & Ve & VIf & VIIg \\
\hline $\operatorname{Rj}$ & 332,5 & 150,5 & 202 & 239 & 299,5 & 395,5 & 397 \\
\hline $\mathrm{Nj}$ & 10 & 7 & 8 & 9 & 9 & 10 & 10 \\
\hline $\mathrm{Nj}$ & 63 & & & & & & \\
\hline Keterangan: & $\begin{array}{l}\text { Angka yang } \\
\text { Wallis pada }\end{array}$ & $\begin{array}{l}\text { uti huruf } k \\
\text { ang keperc }\end{array}$ & $\begin{array}{l}\text { yang berb } \\
\text { aan } 95 \% \text {. }\end{array}$ & berbeda & ta menuru & nonparam & ik Kruskal- \\
\hline Explanation: & Numbers wit & mall letter & Is significa & with $95 \%$ & Kruskal & 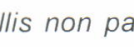 & \\
\hline
\end{tabular}


Tabel 4. Indeks keanekaragaman makrozoobentos di tiap stasiun

Table 4. Diversity index of macrozoobenthos at each station

\section{Stasiun (Station) Indeks keane karagaman (Diversity index) $\mathrm{H}^{\prime}$}

\begin{tabular}{ll}
\hline I & 1.537 \\
II & 1.238 \\
III & 1.455 \\
V & 1.400 \\
VI & 1.537 \\
VII & 1.890 \\
\hline
\end{tabular}

\section{Keanekaragaman}

Hasil penelitian mengenai keanekaragaman makrozoobentos menunjukkan bahwa Indeks Keanekaragaman pada tiap stasiun berkisar antara 1,238 sampai 1,89 (Tabel 4). Dari Tabel 4 terlihat bahwa rata-rata nilai Indeks Keanekaragaman tiap stasiun termasuk ke dalam kategori keanekaragaman sedang, artinya penyebaran jumlah spesies sedang dan kestabilan komunitas sedang (Wilhm, 1975).

\section{Keseragaman}

Dari hasil penelitian diperoleh data Indeks Keseragaman pada tiap stasiun pengamatan berkisar antara 0,636 sampai 0,820 (Tabel 5).

Dari Tabel 5 tersebut dapat diketahui keseragaman tertinggi terdapat pada stasiun VI dan terendah pada stasiun II. Berdasarkan kriteria yang berlaku, nilai kisaran tersebut menunjukkan bahwa kelimpahan individu antar spesies organisme makrozoobentos relatif sedang. Hal ini dapat dilihat dari nilai indeks yang diperoleh mendekati nilai 0,5 kecuali pada stasiun VI dan VII yang mulai mendekati 1, di mana pada stasiun VI dan VII ditemukan 10 spesies makrozoobentos. Nilai keseragaman 1 menunjukkan bahwa keseragamannya tinggi, artinya jumlah individu pada tiap spesies relatif sama dan belum terjadi dominasi yang mutlak dari salah satu spesies. Walaupun ada spesies yang mempunyai kepadatan yang tinggi, seperti spesies Pleurocera acuta (Gastropoda), akan tetapi jumlah individu per spesies dari jenis yang lain tidak berbeda jauh.

\section{Defisit species}

Dari hasil penelitian diperoleh data indeks defisit species pada tiap stasiun pengamatan berkisar antara $-30 \%$ sampai dengan $30 \%$ (Tabel 6 ). Bila nilai indeks 0 berarti tidak terjadi perubahan jumlah spesies pada kedua stasiun yang dibandingkan, sedangkan nilai negatif (-) berarti terjadi penambahan jumlah spesies, dan nilai positif $(+)$ menunjukkan adanya pengurangan jumlah spesies yang terdapat pada dua stasiun yang dibandingkan.

Dari Tabel 6 terlihat bahwa pengurangan jumlah spesies tertinggi terdapat pada stasiun I terhadap stasiun II sebesar 30\%, hal ini berkaitan dengan hilangnya beberapa spesies akibat predasi dan kondisi kualitas air yang menurun, khususnya akibat

Tabel 5. Indeks Keseragaman Makrozoobentos di tiap stasiun

Table 5. Homogenity index of macrozoobenthos at each station

\begin{tabular}{cc}
\hline Stasiun (Station) & Indeks keseragaman (Homogenity index) E \\
\hline I & 0.699 \\
II & 0.636 \\
III & 0.699 \\
IV & 0.637 \\
V & 0.699 \\
VI & 0.820 \\
VII & 0.810 \\
\hline
\end{tabular}


Tabel 6. Spesiesdefisit (\%) antar stasiun pengamatan

Table 6. Defisit species (\%) between stations

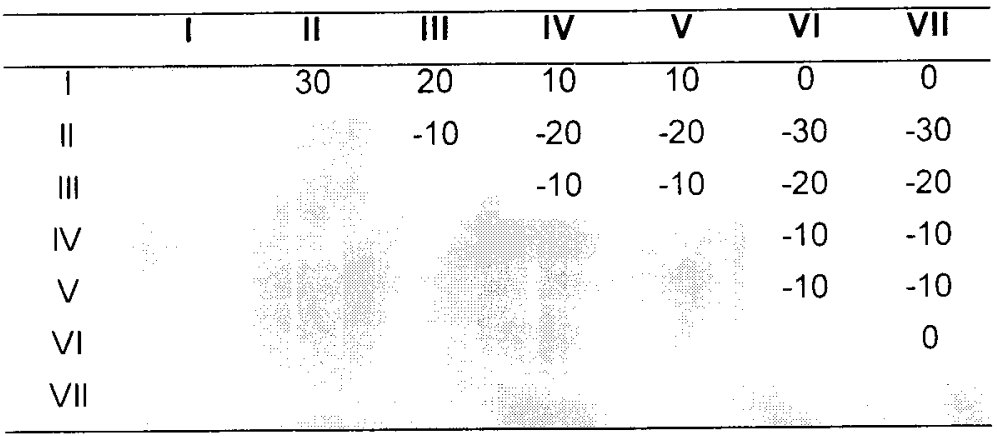

perubahan konsentrasi bahan organik dari stasiun I sampai stasiun II. Sedangkan nilai indeks defisit species terkecil sebesar $-30 \%$ terjadi pada stasiun II dengan VI dan pada stasiun II dengan VII. Hal ini berarti bahwa ada peningkatan yang signifikan terhadap jumlah spesies antara stasiun II dengan stasiun VI dan VII, karena pada stasiun tersebut terjadi akumulasi bahan organik yang merupakan makanan bagi makrozoobentos dan di samping itu pula karena tipe dasar perairan pada stasiun VI dan VII sesuai dengan habitat makrozoobentos.

\section{Analisis isi perut ikan}

Hasil penelitian isi perut ikan nila, tawes, dan jambal dengan metode indeks bagian terbesar (Indexs of Preponderance/IP) diperoleh hasil analisis seperti terlihat pada Tabel 7

Dari Tabel 7 tersebut terlihat terdapat perbedaan bahwa jenis makanan ikan nila, tawes, dan jambal dari sampel yang diteliti. Dari jenis-jenis makanan tersebut, yang berfungsi sebagai makanan utama pada ikan nila dan jambal yaitu makrozoobentos, pada ikan tawes yaitu serasah tumbuhan, sedangkan yang berfungsi sebagai makanan pelengkap pada ikan nila dan jambal yaitu fragmen hewan dan pada ikan tawes yaitu plankton. Jenis-jenis lainnya berfungsi sebagai makanan tambahan

Komposisi makanan ikan nila, pada tiap jenis makanan hampir seimbang, karena ikan nila bersifat omnivora, Sugiarto (1986) menyatakan bahwa ikan nila dapat memanfaatkan segala jenis makanan yang ada di perairan alami, ikan nila memakan plankton, perifiton atau tumbuhan air yang lunak dan cacingcacingan.

Jenis makanan ikan tawes yang paling dominan sekaligus menjadi makanan utamanya yaitu serasah tumbuhan. Serasah tumbuhan yang terdapat dalam alat pencernaan ikan tawes ini umumnya berupa serat-

Tabel 7. Indeks of Preponderance (IP) jenis makanan pada ikan nila, tawes, dan jambal Table 7. Preponderance indexs of Nila tilapia. Java Carp and Catfish

\begin{tabular}{lccc}
\hline \multirow{2}{*}{$\begin{array}{c}\text { Jenis makanan } \\
\text { Kind of feed }\end{array}$} & \multicolumn{2}{c}{ Indeks preponderance (Index of preponderace) \% } \\
\cline { 2 - 4 } & Nila (Nile tilapia) & Tawes (Java carp) & Jambal (Catfish) \\
\hline Bacillarophyceae & 8,13 & 10,22 & 0 \\
Chlorophyceae & 2,73 & 5,12 & 0 \\
Crysophyceae & 0,40 & 3,67 & 0 \\
Crynophyceae & 0 & 0,75 & 0 \\
Serasah tumbuhan & 5,59 & 44,39 & 0,41 \\
Plant fragment & & & \\
Fragmen hewan & 14,66 & 0,02 & 22,63 \\
animal fragment & & & \\
Biji-bijian (seeds) & 0,86 & 1,16 & 0,71 \\
Macrozoobenthos & 26,04 & 0,09 & 40,22 \\
Detritus & 39,59 & 34,58 & 36,03 \\
\hline
\end{tabular}


serat dedaunan, rerumputan, dan lain-lain. Hal ini sesuai dengan pendapat Rochdianto (1995) yang menyatakan bahwa di habitat aslinya ikan tawes tergolong sebagai ikan pemakan tumbuh-tumbuhan. Ardiwinata (1981) menyatakan bahwa makanan ikan tawes dewasa adalah tumbuhan air termasuk jasadjasad renik yang menempel pada tanaman tersebut.

Jenis makanan utama dan pelengkap ikan jambal tidak berbeda dengan ikan nila. tetapi dengan persentase yang lebih besar dan komposisi antar jenis makanan lainnya yang tidak seimbang, diduga karena ikan jambal merupakan ikan karnivora. Menurut Rochdianto (1995), kebiasaan makan ikan jambal yaitu pemakan hewan. Di perairan umum pakan utama ikan jambal yaitu udang renik, serangga, moluska serta pakan pelengkapnya adalah rotifera (Sarnita, 1978).

\section{Variabel fisika perairan}

\section{Arus air}

Hasil pengukuran kecepatan arus selama penelitian berkisar antara 0,15-0,25 m/detik. Menurut Mason (1981) kisaran nilai tersebut tergolong ke dalam perairan yang memiliki arus lambat. Fluktuasi kecepatan arus selama penelitian tidak besar karena pengamatan dilakukan pada areal saluran irigasi tertutup, sehingga fluktuasi arus yang terjadi diduga hanya disebabkan oleh penyempitan saluran (dari saluran primer lebar 8-12m menjadi menjadi saluran sekunder lebar $6 \mathrm{~m})$, hambatan sekat sariban, belokan pada saluran irigasi, atau diperkirakan juga karena adanya pengaruh musim hujan yang terjadi pada saat penelitian berlangsung. Selain itu debit air yang masuk telah diatur oleh petugas pintu air irigasi. Kisaran nilai arus yang didapatkan pada tiap stasiun beragam. Mulai dari stasiun I berkisar antara 0,21-0,25 m/detik, stasiun II 0,15-0,2 m/detik, stasiun III 0,17-0,21 m/ detik, stasiun IV 0,17-0,21 m/detik, stasiun V 0,21$0,23 \mathrm{~m} /$ detik, stasiun VI 0,23-0,25 m/detik, dan stasiun VII 0,21-0,24 m/detik

Secara umum stasiun I dan stasiun VI mempunyai kecepatan arus yang relatif paling tinggi dibandingkan stasiun lainnya, sedangkan pada stasiun II mempunyai kecepatan arus paling rendah. Tingginya kecepatan arus pada stasiun I merupakan daerah pemasukan air dari saluran primer untuk saluran sekunder Kawista (yang menyempit dari 8-12m menjadi $6 \mathrm{~m}$ ) tempat sariban berada, sedangkan pada stasiun VI diperkirakan karena stasiun VI merupakan daerah perubahan dari saluran sekunder ke saluran tertier yang menyempit dari lebar $6 \mathrm{~m}$ menjadi $4 \mathrm{~m}$ saluran tertier Kawista. Sedangkan rendahnya kecepatan arus pada stasiun II diduga disebabkan karena pada stasiun II terdapat sekat-sekat untuk budi daya ikan yang pada pelaksanaannya sering terdapat sampah yang menyangkut pada sekat tersebut. sehingga secara langsung dapat menghambat kecepatan aliran air. Pada stasiun III, IV, V, dan VII kecepatan arus relatif sama karena kurangnya pengaruh-pengaruh seperti yang disebutkan di atas.

\section{Tekstur sedimen}

Adanya perbedaan nilai kecepatan arus tiap stasiun menyebabkan adanya perbedaan komposisi kandungan jenis sedimen di dasar sungai. Berdasarkan hasil analisis komponen pembentuk sedimen dasar perairan didapatkan hasil seperti tertera pada Tabel 8, yang kemudian diplotkan ke dalam segitiga Millar, sehingga didapatkan hasil bahwa seluruh stasiun bertipe sedimen lempung berliat kecuali stasiun VII dengan tipe berliat.

Hal ini dapat terjadi karena rata-rata kecepatan arus di setiap stasiun tergolong lambat. sehingga tidak terlalu berpengaruh terhadap tipe sedimen di

Tabel 8. Tekstur sedimen dari tiap stasiun pengamatan berdasarkan persentase fraksi tanah pada segitiga Millar

Table 8. Sedimen textures of each station based on soil fraction percentage of Millar triangle

\begin{tabular}{ccccc}
\hline \multirow{2}{*}{$\begin{array}{c}\text { Stasiun } \\
\text { Station }\end{array}$} & \multicolumn{3}{c}{ Tekstur (Textur) \% } & \multirow{2}{*}{$\begin{array}{c}\text { Tipe sedimen } \\
\text { Sedimen type }\end{array}$} \\
\cline { 2 - 4 } & Pasir (Sand) & Debu (Dust) & Liat (Pliable) & \\
\hline 1 & 40 & 30 & 30 & Lempung berliat (Clay) \\
2 & 22 & 39 & 39 & Lembang berliat (Clay) \\
3 & 28 & 35 & 37 & Lempung berliat (Clay) \\
4 & 33 & 35 & 32 & Lembang berliat (Clay) \\
5 & 29 & 38 & 33 & Lempung berliat (Clay) \\
6 & 43 & 26 & 31 & Lembang berliat (Clay) \\
7 & 28 & 29 & 43 & Berliat (Pliable) \\
\hline
\end{tabular}


ketujuh stasiun berdasarkan segitiga Millar. Secara langsung pengaruh sariban terhadap tipe sedimen tidak terlihat, akan tetapi secara tidak langsung sariban akan mempengaruhi persentase komponen penyusun tipe sedimen dengan adanya perbedaan arus

Apabila kita melihat persentase kandungan tiap komponen penyusunnya, akan terlihat perbedaan persentase masing-masing komponen penyusun tersebut. Pada stasiun I dan VI dengan kecepatan arus yang relatif lebih besar, persentase pasir terlihat lebih dominan dibandingkan dengan komponen penyusun lainnya. Sedangkan pada stasiun II di mana arus relatif lebih lambat terlihat bahwa persentase debu dan liat lebih dominan. Pada stasiun II, IV, dan $\checkmark$ terdapat keseimbangan antar komponen penyusunnya, sedangkan pada stasiun VII terlihat komponen liat lebih dominan.

Jenis sedimen di perairan sangat penting diketahui karena merupakan faktor pembatas penyebaran organisme bentos. Jenis sedimen ini erat kaitannya dengan kandungan oksigen terlarut dan ketersediaan nutrien dalam sedimen. Untuk jenis sedimen yang berpasir disenangi oleh kelompok Gastropoda, sedangkan untuk sedimen dengan kandungan debu dan liat yang dominan, lebih disenangi oleh kelompok Oligokaeta.

\section{Variabel kimia perairan}

\section{Oksigen terlarut}

Nilai oksigen terlarut yang didapat dari hasil pengukuran di tiap stasiun berkisar antara 4,19-7,25 $\mathrm{mg} / \mathrm{L}$ ( Lampiran 1). Kisaran ini dapat disimpulkan bahwa kondisi perairan di saluran irigasi sekunder Kawista masih baik untuk budi daya perikanan yaitu $>4$ mg/L (Schmitz, 1971). Sebaran nilai oksigen terlarut di tiap stasiun selama pengamatan menunjukkan variasi nilai oksigen terlarut antar stasiun tidak terpengaruh oleh aktivitas budi daya ikan dengan sistem sariban dan cenderung seragam. Ha ini terjadi karena penelitian dilakukan di perairan bertipe air mengalir yang memungkinkan oksigen terlarut terdistribusi secara merata di seluruh badan perairan

\section{Biological Oxygen Demand (BOD)}

Pengukuran BOD mempunyai keuntungan karena dapat dengan mudah menggambarkan jumlah bahan organik yang terurai secara biologis, tanpa perlu mengetahui secara rinci zat-zat organik yang terdapat maupun jenis penguraiannya. Hasil pengukuran BOD selama pengamatan berkisar antara 1,46-6,77 mg/L (Lampiran 1), kisaran nilai BOD tersebut menunjukkan bahwa kualitas air di saluran irigasi sekunder Kawista berada dalam kondisi tidak tercemar sampai tercemar sedang (Lee et al., 1978).

Sebaran nilai BOD pada tiap Stasiun pengamatan berfluktuasi. Fluktuasi nilai BOD di saluran irigasi sekunder Kawista secara umum dipengaruhi oleh adanya aktivitas budi daya ikan sistem sariban di hulu saluran, kecuali pada Stasiun VII. Tingginya nilai BOD di Stasiun III diduga selain karena budi daya ikan, juga akibat adanya aktivitas penduduk dalam mengolah sawah. Nilai BOD terendah terjadi pada Stasiun III yang diperkirakan disebabkan oleh bahan organik dari sisa-sisa metabolisme ikan yang terbawa arus dari areal sariban dan tidak sempat terakumulasi di Stasiun III.

Dari sebaran BOD, terlihat adanya kecenderungan peningkatan BOD dari daerah setelah Sariban menuju ke hilir saluran yaitu mulai dari Stasiun III, IV, dan V tetapi kemudian stabil pada Stasiun V sampai VI. Hal ini memberikan gambaran bahwa bahan-bahan organik yang dihasilkan oleh budi daya ikan sistem sariban yang berupa feces (memperkaya kandungan nitrogen, fosfor, dan karbon), bahan organik yang tidak tercemar, sisa pakan yang tidak terserap akan menjadi bahan anorganik. Penguraian bahan organik itu terjadi secara aerobik pada permukaan sedimen dan anaerobik di dalam sedimen dengan bantuan mikroba seperti bakteri dan fungi. Akhir dari proses penguraian dilepaskan sebagian besar terakumulasi pada daerah antara Stasiun V dan Stasiun VI yaitu pada jarak 25 . $125 \mathrm{~m}$

\section{Derajat keasaman $(\mathrm{pH})$}

Derajat keasaman $(\mathrm{pH})$ yang diukur selama penelitian berkisar antara 7,2-7,5. Secara umum derajat keasaman yang diukur seragam. Fluktuasi nilai pH merupakan pengaruh beberapa hal di antaranya aktivitas budi daya ikan sistem Sariban, kondisi iklim, dan juga kondisi perairan di hulunya. Sebaran nilai $\mathrm{pH}$ tiap stasiun pengamatan disajikan pada Lampiran 1. Nilai $\mathrm{pH}$ terendah terjadi pada stasiun II, IV, dan V serta nilai tertinggi terjadi pada stasiun I.

\section{KESIMPULAN DAN SARAN}

\section{Kesimpulan}

1. Hasil penelitian menunjukkan bahwa pada saluran irigasi Kawista Telagasari Karawang terdapat sebanyak 17 jenis makrozoobentos yaitu Pleurocera acuta. Goniobasilivescen, Lioplax subcarinata, Gyrotoma amplum, Trynia sp. Lithasia sp. Pomacea calignosa, Physa gyrina, Gyraulus sp. (kelas Gastropoda). Simpsoniconcha 
sp., Sphaerium simile (kelas Pelesipoda) Pseudodiamesa sp., Berosus striatus Dasyhela sp., Culocoides variipennis (kelas Insekta) serta Lumbriculus sp., Branchiura sowerbyi (kelas Gastropoda)

2. Kelimpahan makrozoobentos tertinggi yaitu Gastropoda $(57,61 \%)$, diikuti Oligokaeta $(23,66 \%)$, Insekta $(10,02 \%)$, dan terendah Pelesipoda $(8,71 \%)$. Struktur komunitas makrozoobentos di stasiun-stasiun pengamatan pada lokasi sebelum, dalam sariban dan setelah sariban menunjukkan bahwa terjadi perubahan struktur komunitas makrozoobentos terutama untuk kelimpahan makrozoobentos per stasiun, yaitu Stasiun I (1.161 ind $\left./ \mathrm{m}^{2}\right)$, Stasiun II (417 ind $\left./ \mathrm{m}^{2}\right)$, stasiun III (618 ind $\left./ \mathrm{m}^{2}\right)$. Stasiun IV $\left(1.057 \mathrm{ind} . / \mathrm{m}^{2}\right)$. Stasiun $V$ (1.083 ind $\left./ \mathrm{m}^{2}\right)$, Stasiun VI (1.257 ind $\left./ \mathrm{m}^{2}\right)$, dan Stasiun VII (1.194 ind. $\left./ \mathrm{m}^{2}\right)$.

3. Kualitas air mengalami perubahan akibat aktivitas sariban, khususnya untuk BOD.

4. Pada saluran sekunder Kawista dapat dibangun 4 unit sariban dengan jarak antar sariban minimum $125 \mathrm{~m}$.

\section{Saran}

Berdasarkan hasil penelitian mengenai kelimpahan makrozoobentos pada saluran irigasi sekunder Kawista dengan kecepatan arus rata-rata 0,2 m/det. dan debit air 63 L/det., maka disarankan agar jarak antar sariban minimal 125 meter

\section{DAFTAR PUSTAKA}

APHA (American Public Health Association). 1989 Standard Methods for the Examination of Water and Waste Water. 17 ed. APHA. AWWA and WPCF. Washington D.C. 3464 pp

Anonim. 1998. Kerja sama antara Balitkanwar dengan Perum Otorita Jatiluhur. Laporan Penelitian Inventarisasi Potensi Sumber Daya Perairan Saluran Irigasi untuk Pengembangan Usaha Perikanan dengan Sistem Sariban. Balitkanwar. 40pp.

Anonim. 1997. Rencana Strategis Penelitian Perikanan Air Tawar Tahun 1997-2007. Pusat Penelitian dan Pengembangan Perikanan. Balai Penelitian Perikanan Air Tawar. 49 pp.

Ardiwinata, R.O. 1981. Pemeliharaan Ikan Tawes. Jilid II. Sumur Bandung. Bandung. 100 pp.

Barnes, R.S.K. and K. Mann. 1991. Fundamentals of Aquatic Ecosystem. Blackwell Scientific Publication. Oxford. London. 395 pp.

Effendie. 1978. Biologi Perikanan. Bagian I. Studi Natural History. Fakultas Perikanan IPB. Bogor. 105 pp.

Hellawell, J.M. 1989. Biological Indicator of Freshwater Pollution and Environmental Management. Elsevier Science Publisher LTD. England 546 pp.
James, A. and Evinson. 1979. Biological Indicator of Water Quality. John Wiley 8: Sons. Chichester. New York.297 pp.

Klein, L. 1972. River Pollution. Vol 2: Causes and Effect Butterworth and Co. (Publiser). London. 335 pp.

Klemm, D.J. Philip A. Lewis, F. Fulk and J.M. Lazorehak. 1990. Macroinvertebrate Field and Laboratory Methods for Evaluating the Biological Integrity of Surface Waters. EPA. Washington. DC. 256 pp

Lee. C.D., S.B. Wang, \& C.L. Kuo. 1978. Benthic Macroinvertebrate and Fish as Biological indicators of Water Quality. With reference to community Diversity Index. International Conference on Water Pollution Control in Developing Country. Bangkok. $358 \mathrm{pp}$.

Magurran, A.E. 1988. Ecological Diversity and Its Measurement. Princeton University Press. Princeton. New jersey. 177 pp

Mason, C.F. 1981. Biology of Freshwater Pollution. Scientific and Technology. Longman Singapore Publihser Pte. Ltd. Singapore. $250 \mathrm{pp}$

Nasution, A.H. dan A. Barizi 1985. Metode Statistika. Cetakan VI. Penerbit PT Gramedia. Jakarta. 197 pp.

Odum, E.PP. 1971. Fundamental of Ecology. W.B. Aunders Company. Philadelphia 574 pp.

Pennak, R.W. 1978. Freshwater Invertebrates of United States. Second Edition. A Welley Inter Science Publication. John Willey and Sons. Inc. New York. $769 \mathrm{pp}$.

Pescod, N.B. 1973. Investigation of Rational Effluent and Stream for Tropical Countries. AIT. Bangkok. 59 pp.

Persson, L.E. 1983. Temporal and Spatial Variation in Coastal Macrobenthic Community Structure. Hano Bay (Souther Baltic) Vol. 68.154 pp.

Purnomo, K. 1989. Struktur Komunitas Makrozoobentos dalam Kaitan Pemantauan Dampak Aktivitas Manusia di Daerah Sungai Cikao Kab. Purwakarta. Jabar. Program Pasca Sarjana IPB. Bogor. 65 pp.

Rochdianto, A. 1995. Budi Daya Ikan di Saluran Irigasi. Penerbit Kanisius. Cetakan Pertama. Yogyakarta. 72 pp.

Sarnita, A. 1978. Beberapa aspek biologi ikan jambal di Waduk Jatiluhur. Pewarta Lembaga Penelitian Perikanan Darat. Bogor. 54 pp.

Schmitz, W. 1971. General Limnological and Biological Stream Survey as Simple Means of Detecting Pollution and Controlling Their Effects. Pergamon Press. London. $145 \mathrm{pp}$

Sugiarto. 1986. Tehnik Pemijahan Ikan Nila dan Mujair. CV Pusaka Alam Jakarta. 56pp.

Thorp, J.H. and A.PP. Covich.1991. Ecology and Classification of North American Freshwater Invertebrates. Academic Press. Inc. New York. 638 pp.

Welch, E.B. 1975. Ecological Effects of Waste Water. Cambridge University Press. Cambridge. 337 pp.

Wilhm, J.L. 1975. Biological indicator of pollution. In. B.A Whitton (Ed). River Ecology II. Blackwell Sci. Publ. Oxford. London. 735 pp. 
Lampiran 1. Kualitas air di saluran irigasi Kawista Karawang (Oktober-November 1998) Arnex 1. Water quality of irigation canal Kawista Karawang (October-November 1998)

Minggu (Week) Stasiun (Station) Arus (Current) $\mathrm{m} /$ detik DO (mg/L) BOD (mg/L) pH

2

3

4

5

6

\begin{tabular}{|c|c|c|c|c|c|}
\hline \multirow[t]{7}{*}{1} & $T$ & 0.23 & 5.61 & 2.43 & 7.40 \\
\hline & $\|$ & 0.16 & 5.16 & 5.25 & 7.30 \\
\hline & III & 0.18 & 6.60 & 1.47 & 7.40 \\
\hline & IV & 0.18 & 5.80 & 2.26 & 7.30 \\
\hline & V & 0.21 & 5.00 & 3.87 & 7.30 \\
\hline & VI & 0.25 & 4.35 & 4.20 & 7.40 \\
\hline & VII & 0.25 & 4.68 & 2.58 & 7.40 \\
\hline \multirow[t]{7}{*}{2} & 1 & 0.22 & 6.62 & 1.82 & 7.40 \\
\hline & $\|$ & 0.17 & 5.81 & 2.74 & 7.40 \\
\hline & III & 0.20 & 6.30 & 2.58 & 7.30 \\
\hline & IV & 0.20 & 5.83 & 2.90 & 7.40 \\
\hline & V & 0.22 & 4.51 & 2.58 & 7.40 \\
\hline & VI & 0.24 & 5.16 & 2.13 & 7.50 \\
\hline & VII & 0.21 & 4.19 & 1.46 & 7.30 \\
\hline \multirow[t]{7}{*}{3} & 1 & 0.21 & 6.54 & 3.06 & 7.30 \\
\hline & $\|$ & 0.15 & 5.29 & 4.19 & 7.40 \\
\hline & III & 0.18 & 6.80 & 4.84 & 7.40 \\
\hline & IV & 0.18 & 5.80 & 5.32 & 7.30 \\
\hline & V & 0.22 & 5.64 & 6.77 & 7.30 \\
\hline & VI & 0.23 & 5.64 & 4.35 & 7.40 \\
\hline & VII & 0.22 & 6.13 & 4.51 & 7.30 \\
\hline \multirow[t]{7}{*}{4} & 1 & 0.25 & 6.86 & 3.88 & 7.50 \\
\hline & $\|$ & 0.20 & 5.75 & 4.84 & 7.40 \\
\hline & III & 0.21 & 5.64 & 3.22 & 7.40 \\
\hline & IV & 0.21 & 6.29 & 4.52 & 7.30 \\
\hline & V & 0.23 & 6.29 & 5.16 & 7.40 \\
\hline & VI & 0.23 & 6.61 & 6.29 & 7.40 \\
\hline & VII & 0.22 & 6.45 & 6.13 & 7.40 \\
\hline \multirow[t]{7}{*}{5} & 1 & 0.24 & 6.61 & 3.87 & 7.40 \\
\hline & $\|$ & 0.19 & 6.37 & 4.04 & 7.20 \\
\hline & III & 0.21 & 7.09 & 2.90 & 7.40 \\
\hline & IV & 0.21 & 7.25 & 3.55 & 7.30 \\
\hline & V & 0.22 & 6.77 & 3.38 & 7.30 \\
\hline & $\mathrm{VI}$ & 0.25 & 5.96 & 3.22 & 7.40 \\
\hline & VII & 0.24 & 7.25 & 4.83 & 7.40 \\
\hline \multirow[t]{7}{*}{6} & 1 & 0.24 & 6.93 & 2.10 & 7.50 \\
\hline & $\|$ & 0.20 & 7.00 & 3.22 & 7.30 \\
\hline & III & 0.21 & 6.77 & 1.46 & 7.40 \\
\hline & IV & 0.21 & 6.77 & 3.23 & 7.40 \\
\hline & V & 0.22 & 5.64 & 2.10 & 7.30 \\
\hline & VI & 0.24 & 7.25 & 3.23 & 7.30 \\
\hline & VII & 0.23 & 5.64 & 5.97 & 7.40 \\
\hline
\end{tabular}

